\title{
A multilevel analysis of factors influencing local social interaction
}

\author{
Pauline van den Berg ${ }^{1}$ - Theo Arentze ${ }^{2} \cdot$ Harry Timmermans ${ }^{3}$
}

Published online: 29 August 2015

(C) The Author(s) 2015. This article is published with open access at Springerlink.com

\begin{abstract}
Social interaction is an important aspect of people's quality of life. Since social networks are becoming more spatially spread as a result of the development of transportation and communication technology, it is interesting to investigate to which extent local social interactions still take place. This paper therefore analyses to what extent local social interactions are affected by characteristics of the residential environment as well as personal and mobility attributes. The analyses are based on data collected in 2008 in Eindhoven and a number of smaller surrounding villages in the south of the Netherlands among 747 respondents. The data collection instrument consisting of a two-day social interaction diary was used to gather detailed information about the respondents' interactions and the persons they contacted. Using these data a multilevel binomial logit model is estimated analyzing whether or not a social interaction took place with a local tie (someone within $1 \mathrm{~km}$ distance). The results indicate that the likelihood of interacting with a local tie is affected by personal characteristics (age, gender, household size, work), mobility characteristics (number of cars, commuting time), size of the community and the presence of facilities (supermarket, sports, public transport) in the residential area.
\end{abstract}

Pauline van den Berg p.e.w.v.d.berg@tue.nl

Theo Arentze

t.a.arentze@tue.nl

Harry Timmermans

h.j.p.timmermans@tue.nl

1 Eindhoven University of Technology, VRT 8.33, PO Box 513, 5600MB Eindhoven, The Netherlands

2 Eindhoven University of Technology, VRT 8.28, PO Box 513, 5600MB Eindhoven, The Netherlands

3 Eindhoven University of Technology, VRT 8.18, PO Box 513, 5600MB Eindhoven, The Netherlands 
Keywords Social contact $\cdot$ Local tie $\cdot$ Social interaction $\cdot$ Residential location $\cdot$ Logistic regression

\section{Introduction}

Recently, the importance of studying social activity-travel behavior has been recognized in the field of transportation, as social activities account for a large part of trips and are responsible for the fastest growing segment of travel (Axhausen 2005). The distance patterns between social network members are paramount in explaining social activitytravel. Travel distances for social activities are growing, as peoples' social networks are more spatially spread than before (Schlich et al. 2004; Larsen et al. 2006; McPherson et al. 2006). As a result of the development of mobility tools (transportation modes as well as communication technology), social networks can be remained over long distances.

The fact that social networks can be remained over longer distances, has caused local networks to lose importance (e.g. Wellman 1979, 2001; Guest and Wierzbicki 1999). It is however interesting to investigate to which extent local social interactions still take place. The literature agrees that neighbor relations are typically weak (e.g. Granovetter 1973; Fischer 1982; Van der Poel 1993), however, they are important for individuals' resources and for creating sense of community and social cohesion (Granovetter 1973). Although the importance of local communities is declining, "neighborhood ties continue to be important for a sizeable proportion of the population" (Bridge 2002).

The changing importance of local social interaction has caused an increased research interest in the relationship between neighborhood characteristics and sociability. For instance du Toit et al. (2007) and Hanibuchi et al. (2012) have recently studied the relationships between walkability, social contact and social capital in the neighborhood, and Delmelle et al. (2013) studied the neighborhood and transportation-related factors that influence individuals' social satisfaction. Furthermore, in Western European urban renewal policies, great importance is attributed to local social interactions in improving urban areas facing problems regarding livability, unemployment, poverty, social segregation and social exclusion (Kleinhans 2004). Thus far, empirical research into the factors influencing local social interaction is scarce and the findings are inconclusive, which is probably due to differences in methods and study location (Atkinson and Kintrea 2001; Kleinhans 2004; Galster 2007; Pinkster and Völker 2009).

This study therefore aims to investigate to what extent the neighborhood still plays a role for people's social contacts. It does so by answering the question: how likely are people to interact with a local person versus a person living further away, and how is this likelihood affected by mobility attributes, personal characteristics, and characteristics of the residential environment?

Studying the relationship between local social interaction, mobility characteristics and characteristics of the built environment is relevant from a transportation policy and planning perspective. Local social interactions involve only short travel distances, where walking is the dominant mode. People who frequently have social contact with their alters living close by may thus have a smaller demand for longer distance (motorized) social trips. From an urban planning point of view, it is also important to know how characteristics of the residential area can stimulate local social interactions. 
To answer our research question, a multi-level binary logistic regression model is estimated based on social interaction diary data collected in 2008 in the city of Eindhoven, and a number of smaller surrounding villages among 747 respondents.

The structure of the paper is as follows. The next section describes the literature on the factors influencing social interaction with local ties. Section "Data collection, variables and descriptives" presents the data collection and descriptive statistics. In Section "Methods and results" the results of the multilevel binomial logit model are presented. Finally, Section "Conclusions and discussion" contains the conclusions and discussion.

\section{Local social interaction}

This section reviews the existing literature on social activity-travel behavior and the factors that may affect local social interactions. We focus on three categories of variables that are likely to affect local social interaction, namely personal or household characteristics, mobility characteristics and characteristics of the residential location.

As social interaction is an important aspect of people's quality of life, it has recently been studied in a number of different contexts. For example, Putnam (2000), Forrest and Kearns (2001) and Van Kempen and Bolt (2009) focused on social interaction in relation to social capital and social cohesion. Farber et al. (2013) and Neutens et al. (2013) discussed social interaction potential of regions based on a time-geographic framework. The relation between face-to-face social interaction and social interaction mediated by information and communication technology (ICT) has been studied by Baym et al. (2004), Boase et al. (2006), Mokhtarian et al. (2006), Tillema et al. (2010) and Van den Berg et al. (2012).

In the field of transportation, the study of social networks and related social activitytravel behavior has been recognized as a research frontier (e.g. Dugundji et al. 2011). Data collection and empirical analyses have focused on travel frequency (or face-to-face contact frequency), travel distance (or the distance between homes of the contacting persons) and transport mode choice (e.g. Larsen et al. 2006; van den Berg et al. 2009; Van den Berg et al. 2011; Carrasco and Miller 2006; Carrasco and Cid-Aguayo 2012; Kowald and Axhausen 2012). Arentze and Timmermans (2008) proposed a framework to incorporate social activities and social networks in the micro simulation of activity-travel patterns. Ronald et al. (2011; 2012) modeled social activities using agent-based simulation.

These, and other studies from different fields have demonstrated that the likelihood of interacting with alters who live close are associated with personal and household characteristics. It is generally acknowledged that the chances of meeting fellow residents increase when people spend more time in the area where they live (e.g. Guest and Wierzbicki 1999; Völker and Flap 2007). We therefore expect that people who spend more time at home or in the neighborhood are more likely to interact with local alters. There are different conditions that cause people to spend more time in their residential area. For instance, people with young children and people who do not work are likely to spend more time at home. The same goes for older (retired) people. It is often suggested that older people are particularly dependent on neighbors for social contacts. Völker and Flap (2007) indeed found the likelihood of having at least one neighbor in their social network is higher for older people. However, Thomése and van Tilburg (2000) did not find age to affect the proportion of neighbors in people's network.

Regarding the role of socio-economic status, the results of different studies are sometimes inconsistent. For instance, Van der Poel (1993) found that more educated people have more neighbors in their networks than less educated people, whereas Van Eijk (2010) 
found that the number of local ties was similar for people with a lower and higher level of education, but the share of local ties in the network was larger for less educated people. The different findings between Van der Poel and Van Eijk might be due to an interaction effect of personal education or income level and neighborhood education or income. People with a higher level of education or income may have more locally oriented networks when they live amongst other high income or more educated residents. In other words, people may have more local social interaction if they live among others who are more like them (Völker and Flap 2007; Hipp and Perrin 2009). Studying personal networks in northern California, Fischer (1982) found social networks of low educated, low-income, and minority residents to be more locally oriented. According to Van Beckhoven and Van Kempen (2003) this may be related to the fact that activities and transport cost money, resulting in a smaller action radius for lower income households. Although significant effects of education and income on local social interaction were found in a number of studies, it is not clear how exactly these mechanisms work.

A final personal characteristic that might affect interaction with local alters is the composition of one's personal social network and the amount of social interaction with non-local alters. One's social network consists of alters with different roles (e.g. neighbors, colleagues, friends, relatives), living at different distances. Local alters can include fellow residents (people met through living in proximity) as well as friends or relatives who live close by (people met in a different context). Whereas ties with friends and relatives are likely to be strong, neighbor relations tend to be weak (e.g. Granovetter 1973). They may however be very important for people. Völker and Flap (2007) suggest that "neighbors become the first (and only) choice" for people without other social network members, although they did not find strong empirical support for this. On the other hand, Van Eijk (2010) found that "people with small networks do not seem to compensate for their small network by forming more ties with fellow residents". This finding suggests that personal social network size does not affect the likelihood of interacting with local alters.

A second group of variables that are likely to affect local social interaction are people's mobility characteristics. The availability of transportation resources such as car availability or season ticket for public transport has been found to increase the physical distance in one's social network (Kowald et al. 2013). It may thus increase the likelihood of interacting with alters outside the neighborhood. In addition, commuting time can be important in explaining local social contact, as this is also related to the time available for social contact and the time people spend at home. Therefore, people with longer commuting times may be less likely to interact with local alters. In the same fashion, Delmelle et al. (2013) found that people with a longer commuting time are less satisfied with their social contacts. We thus expect people who are more mobile to be less likely to interact with local alters.

A third group of variables that may affect local social contact consists of characteristics (and perception) of the residential location. For instance, a longer residence in the neighborhood has been found to increase neighborhood-based social contacts (e.g. Hipp and Perrin 2009) and social satisfaction (Delmelle Delmelle et al. 2013). Local facilities are expected to increase opportunities for social interaction among residents (e.g., Oldenburg 1989; Talen 1999; Völker and Flap 2007; Dempsey et al. 2012; Francis et al. 2012; Hickman 2013). Studying the importance of third places for social interaction based on 180 in-depth interviews with residents from six deprived neighborhoods across Great Britain, Hickman (2013) found that shops are particularly valued for social interaction by all residents. Other public facilities, such as parks and community centers were also found to be important, especially by people who spend more time at home, such as retired or 
unemployed people, people with poor health and people with children at home. In addition, schools can be a setting to develop and maintain social contact with fellow residents (Van Beckhoven and Van Kempen 2003; Völker and Flap 2007; Van Eijk 2010). According to the study by Francis et al. (2012) Public Open Space, community centers, schools and shops are the most common public spaces for social interaction within the neighborhood.

Some studies have also found other neighborhood characteristics to affect local social interaction, for instance neighborhood income, which is also related to ethnicity, type of housing, urban density, social safety and residential mobility. The literature seems to agree that people in neighborhoods with a larger degree of urbanization have a smaller proportion of neighbors in their social network (e.g. Fischer 1982; Thomése and van Tilburg 2000). Thomése and van Tilburg (2000) also found a negative effect of residential mobility in the neighborhood on the size of neighboring networks of elderly people in the Netherlands. Fischer (1982) found lower contact frequencies between neighbors in lowincome neighborhoods compared to higher income neighborhoods. According to Fischer this is due to the fact that there is more variety in race, ethnicity and occupation in lowincome neighborhoods. This again suggests that similarity in background characteristics enhances neighborhood contacts. This is also related to collective efficacy, which is a form of social organization that combines social cohesion and shared expectations for social control (Sampson 2006).

Whereas other studies have found local social interaction to be affected by neighborhood characteristics, we did not find these effects in a recent study on quality of life in Eindhoven (Van den Berg et al. Van den Berg and Timmermans 2013). We found no significant effect of neighborhood income, urban density, housing tenure, residential mobility or ethnicity on the frequency of contact with neighbors or the share of neighbors in one's social network. Van Eijk (2010) did not find neighborhood income to affect social contacts. She studied whether living in a poor neighborhood results in network poverty, which she defined as "having a personal network including merely or mostly resource-poor people and, thus, lacking ties to resources such as knowledge, wealth, skills, power and information". She concluded that network poverty is not so much related to neighborhood characteristics, but rather to a lack of participation in certain settings such as study, work, leisure and associations. Kleinhans (2004) also concludes that lifestyle is far more important than neighborhood characteristics such as tenure to explain social interaction.

As suggested by this brief overview of literature, local social interactions may be related to a number of personal and mobility characteristics and characteristics of the residential environment. However, as the results from different studies remain inconclusive, more empirical evidence is required. This study will therefore analyze the factors influencing social interaction with local ties based on data collected in the region of Eindhoven, the Netherlands. The following section discusses the data collected for this study.

\section{Data collection, variables and descriptives}

In order to collect data for this study, we used the social network approach. This approach has been developed in sociology (e.g. Wasserman and Faust 1994) and regards social networks as a composition of nodes (people) and links (the ties between people). For given individuals (egos) the personal network members (alters) are elicited in this approach.

For this study, a social interaction diary was used to reveal the alters with whom the ego (respondent) has social contact. In the social interaction diary that was designed for this 
study, respondents aged 15 or over were asked to record their social interactions during two consecutive days. Social interaction was defined as contact that went beyond just greeting others, and that was more social than business-like (e.g., work contacts strictly about work matters were not included, and nor were contacts with unknown shop assistants when only paying for merchandise). The fact that greetings were not recorded in the diaries may result in an underrepresentation of social interactions with weak ties (which local alters often are) in our study, just like in most social network measurement instruments. As weak ties are especially important for creating sense of community and social cohesion (Granovetter 1973), we should to be very careful to draw conclusions regarding these mechanisms based on our analysis.

Social interaction could be face-to-face as well as via other communication modes, such as telephone calls, text messages and e-mails. Respondents were instructed not to record interactions at home with just members of the household. Interactions at home with others (visitors) were included, as well as interactions with household members outside the home.

Respondents were asked to record several aspects of each social interaction, including the communication mode used for the interaction, the day of the week, the time and duration of the interaction, whether the social interaction was routine, pre-arranged or spontaneous, the purpose of the interaction, and where the interaction took place. In addition, they were asked to record detailed information about every person with whom they interacted during those 2 days. These questions included age, gender and social category of this person, how long the respondent has known this person, the strength of the relationship with this person, the distance between the homes of the respondent and this person and the frequency of social contact with this person by different communication modes. The distance between homes of the respondent and contacted alter was measured in categories $(0-1,1-2 \mathrm{~km}, 2-5,5-15,15-30,30-60,60-100,100-200 \mathrm{~km}$, more than $200 \mathrm{~km}$, namely $X \mathrm{~km}$ ).

In addition, the interaction diary contained a questionnaire on personal and household characteristics of the respondents such as age, gender, household composition, level of education, income, occupation, social network size, whether or not they are (somewhat) physically challenged and available transportation tools (number of cars, season ticket for public transport), as well as characteristics of the residential environment (distance to different types of facilities).

The data were collected between January and March 2008 in the city of Eindhoven, and a number of smaller surrounding villages (Geldrop, Sint Oedenrode, Nijnsel, Liempde, Gerwen and Son). Eindhoven is a medium-sized city in the south of the Netherlands. To make sure there was sufficient variation in our sample regarding characteristics of the built environment, the sample was stratified by urban density. A number of neighborhoods in the city of Eindhoven and the surrounding villages were chosen based on urban density. In these neighborhoods addresses were randomly selected. Figure 1 shows a map of the area with the sampled neighborhoods. To increase the participation of respondents, a personal approach was employed. Respondents were visited at home to ask them if they were willing to participate in this study. The visits took place at varying times of day, also in the evening, to include working people. Still, there may be some bias in the sample of people who were not home (and possibly more likely to be socializing). On the other hand a selfselection bias is possible in the sense that more sociable people are more willing to participate in a study on social interaction. As an incentive, 35 vouchers of $€ 25,00$ were allocated to respondents through a lottery system. In total, 3699 people were asked to participate. Out of these 3699, 1648 (45 \%) accepted a diary and 747 useful diaries were 


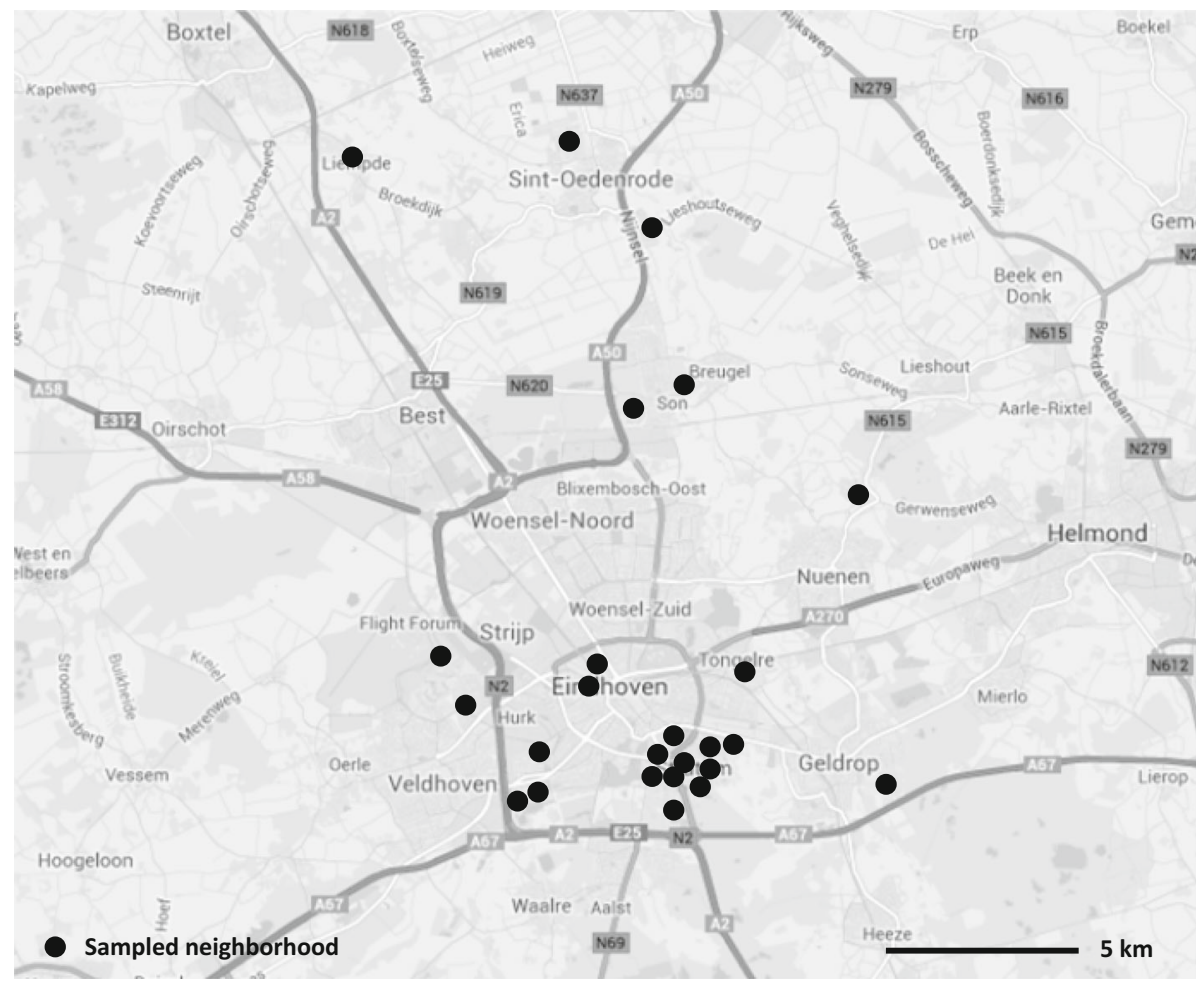

Fig. 1 Spatial distribution of sampled neighborhoods

returned. This results in an overall response rate of $20 \%$, which is good for this type of survey.

Respondents were asked to keep the diary for two successive days. They were given a choice of which day of the week they started. We made this decision because we had serious concerns about the response rates if we added too many restrictions. However, it is possible that there is some bias because of this decision. Some respondents may have reported their social interactions for less active days to reduce their efforts, whereas others may have chosen to report their more 'interesting' days with relatively many interactions. Fortunately, diary days are distributed fairly even across the days of the week.

Table 1 shows the descriptive statistics of the sample of respondents. As shown, the average age of the respondents is 46.5 , which means that older people are somewhat overrepresented. The results show that $39 \%$ of the sample are men. This indicates that women are overrepresented in the sample. On average, the respondents work $20 \mathrm{~h}$ per week. Regarding household size Table 1 shows an average of 2.9, which is higher than the average household size of 2.2 in the Netherlands. This is due to an underrepresentation of single person households in the sample. $23 \%$ of the respondents have a primary education, whereas $46 \%$ have completed higher education. When compared with census data of the Dutch population it is clear that more educated people are somewhat overrepresented. $28 \%$ of the respondents have a net income under 2000 per month and $33 \%$ have a net income of $€ 3000$ or more. 
Table 1 Sample characteristics $(\mathrm{N}=747)$

\begin{tabular}{|c|c|c|c|c|c|}
\hline & Mean & St. dev. & $\min$ & $\max$ & Mean NL \\
\hline \multicolumn{6}{|l|}{ Level-1 Social interaction $N=7339$} \\
\hline With alter living within $1 \mathrm{~km}$ (dependent variable) & 0.14 & 0.35 & 0 & 1 & \\
\hline On a weekend day & 0.20 & 0.40 & 0 & 1 & \\
\hline \multicolumn{6}{|l|}{ Level-2 respondent $\mathrm{N}=742$} \\
\hline \multicolumn{6}{|l|}{ Personal characteristics } \\
\hline Age & 46.47 & 15.31 & 15 & 89 & 40.10 \\
\hline Male & 0.39 & 0.49 & 0 & 1 & 0.49 \\
\hline Works full time ( $\geq 36 \mathrm{~h}$ per week) & 0.27 & 0.44 & 0 & 1 & 0.34 \\
\hline Household size & 2.89 & 1.31 & 1 & 10 & 2.22 \\
\hline Secondary education & 0.31 & 0.42 & 0 & 1 & 0.43 \\
\hline High education (BSc or higher) & 0.46 & 0.50 & 0 & 1 & 0.28 \\
\hline Medium income (€2000-3000 net/month) & 0.39 & 0.45 & 0 & 1 & 0.25 \\
\hline High income (>€3000 net/month) & 0.33 & 0.47 & 0 & 1 & 0.50 \\
\hline Social network size & 22.14 & 20.70 & 0 & 240 & \\
\hline (Somewhat) physically challenged & 0.10 & 0.30 & 0 & 1 & \\
\hline Lives $<2$ years in neighborhood & 0.15 & 0.36 & 0 & 1 & \\
\hline Feels completely at home in neighborhood & 0.35 & 0.48 & 0 & 1 & \\
\hline \multicolumn{6}{|l|}{ Mobility characteristics } \\
\hline \# Cars in household & 1.28 & 0.70 & 0 & 4 & \\
\hline Public transport season ticket & 0.26 & 0.44 & 0 & 1 & \\
\hline Commuting time (minutes) & 15.32 & 17.91 & 0 & 160 & \\
\hline \multicolumn{6}{|l|}{ Neighborhood perception } \\
\hline Lives in Eindhoven & 0.78 & 0.42 & 0 & 1 & \\
\hline Supermarket within $1 \mathrm{~km}$ & 0.73 & 0.44 & 0 & 1 & \\
\hline Primary school within $1 \mathrm{~km}$ & 0.75 & 0.44 & 0 & 1 & \\
\hline Outdoor sports facility within $1 \mathrm{~km}$ & 0.34 & 0.48 & 0 & 1 & \\
\hline Indoor sports facility within $1 \mathrm{~km}$ & 0.32 & 0.47 & 0 & 1 & \\
\hline Community center within $1 \mathrm{~km}$ & 0.44 & 0.50 & 0 & 1 & \\
\hline Café/bar within $1 \mathrm{~km}$ & 0.27 & 0.44 & 0 & 1 & \\
\hline Restaurant within $1 \mathrm{~km}$ & 0.31 & 0.46 & 0 & 1 & \\
\hline Bus/train stop within $1 \mathrm{~km}$ & 0.89 & 0.32 & 0 & 1 & \\
\hline$\%$ low income households in neighborhood & 34.30 & 13.58 & 5 & 66 & \\
\hline
\end{tabular}

Table 1 shows that the respondents on average have 22 members in their social network. To measure social network size, two questions were used; one asking about the number of very close ties, and one about somewhat close ties. The formulation of the questions was as follows: "Think about the people you feel very close to. They are people with whom you discuss important matters, or regularly keep in touch with, or who are there for you if you need help. They can be household members, relatives, colleagues or fellow students, neighbors, club members and (other) friends. How many people do you feel very close to?" and "Think about the people you feel somewhat close to. They are people who are more than just casual acquaintances, but not very close. They can be household 
members, relatives, colleagues or fellow students, neighbors, club members and (other) friends. How many people do you feel very close to?" Social network size was defined as the sum of very close and somewhat close ties.

$10 \%$ of the respondents indicated they had a disability that hindered them (somewhat) in their mobility. Regarding the mobility characteristics, Table 1 shows that the respondents on average have 1.3 cars in their household, and $27 \%$ has a season ticket for public transport. Regarding the characteristics of the residential environment, we asked respondents about the distance to several facilities (supermarket, primary school, sports facilities, community center, café/bar, restaurant and a public transport stop), because literature shows that these are most likely to affect local social contacts. The perceived distances to the different facilities were measured in categories $(<1,1-2,2-5$, or $>5 \mathrm{~km})$. For the analysis they were recoded into dummy variables ( 1 if the facility is available within $1 \mathrm{~km}$, 0 if the facility is located further away), because $1 \mathrm{~km}$ reflects an acceptable walking distance, and we also used the $1 \mathrm{~km}$ distance to define 'local'. Table 1 shows that $74 \%$ has a supermarket within $1 \mathrm{~km} ; 75 \%$ of the respondents have a primary school within $1 \mathrm{~km}$; $34 \%$ has an outdoor sports facility and $32 \%$ have an indoor sports facility in the neighborhood; $44 \%$ have a community center; $27 \%$ have a café or bar; $31 \%$ have a restaurant and $89 \%$ have a bus stop or train station within $1 \mathrm{~km}$ from home. $79 \%$ of the respondents live in the city of Eindhoven, and $21 \%$ in one of the surrounding villages. $15 \%$ of the respondents have been living in the neighborhood up to 2 years and the other $85 \%$ have been living in their neighborhood longer than 2 years. About one-third of the respondents agree completely with the statement "I feel completely at home in their neighborhood". This was measured on a five point scale ranging from completely disagree to completely agree.

Finally, we obtained a number of neighborhood characteristics from Statistics Netherlands (CBS), including income, type of housing, household composition and urban density. Table 1 shows that the percentage of low income households in the neighborhood ranges between 5 and $66 \%$, with an average of $34 \%$. We only include this variable in the analyses, as it strongly correlates with the other variables, such as the percentage of owner occupied houses $(\rho=-0.84)$, the percentage of single person households $(\rho=0.92)$, the percentage of non-western immigrants $(\rho=0.71)$ and degree of urban density ( $\rho=-0.76)$ ranging from 1 (2500 addresses per square kilometer) to 5 (less than 500 addresses per square kilometer).

In total, the 747 respondents recorded 8074 social interactions in 2 days. This means that the average number of social interactions per respondent per day is 5.4. The social interactions of a respondent are not necessarily with different alters. The number of social interactions per day largely depends on the definition of social interaction and is therefore difficult to compare to other studies. The average number of social interactions per day is similar to findings of Baym et al. (2004) who used a communication diary to assess the relative number of social interactions college students conducted online, compared to faceto-face interactions and telephone calls. However, other studies found different numbers of social interactions per day. For instance, Fu (2007) used the interaction diary to elicit respondents' social network members, and therefore asked them to record all their interactions, including saying hello. He therefore found higher numbers of interactions: an average of 21 interactions per day. As discussed, our sample only includes contacts that went beyond fleeting interactions such as greeting others.

The number of interactions per respondent (in 2 days) varied between 1 and 42. The number of interactions vary among different groups of respondents, as can be seen in Table 2. The results show that the number of interactions decreases with age, with a mean 
Table 2 Mean number of interactions in 2 days by socio-demographics $(\mathrm{N}=747)$

\begin{tabular}{|c|c|c|c|}
\hline & Mean \# interactions & $\mathrm{F}$ & Sig. \\
\hline \multicolumn{4}{|l|}{ Age } \\
\hline $15-35$ & 12.8 & 11.33 & 0.000 \\
\hline $36-50$ & 11.8 & & \\
\hline $51-65$ & 9.9 & & \\
\hline $65+$ & 8.8 & & \\
\hline \multicolumn{4}{|l|}{ Gender } \\
\hline Male & 9.9 & 18.01 & 0.000 \\
\hline Female & 12.0 & & \\
\hline \multicolumn{4}{|l|}{ Education } \\
\hline Low & 8.7 & 17.88 & 0.000 \\
\hline Medium & 11.3 & & \\
\hline High & 12.4 & & \\
\hline \multicolumn{4}{|l|}{ Income } \\
\hline Low & 9.8 & 6.40 & 0.002 \\
\hline Medium & 11.7 & & \\
\hline High & 11.8 & & \\
\hline \multicolumn{4}{|l|}{ Work status } \\
\hline No work & 10.2 & 9.473 & 0.000 \\
\hline Part time & 12.5 & & \\
\hline Full time & 10.6 & & \\
\hline \multicolumn{4}{|l|}{ Eindhoven } \\
\hline Yes & 11.3 & 0.49 & 0.483 \\
\hline No & 10.9 & & \\
\hline
\end{tabular}

of 12.8 for the youngest age group and 8.8 for the oldest age group. Regarding gender, the number of interactions is higher for women. The number of interactions is also higher for high income and more educated respondents. Regarding work status Table 2 shows that part time workers have more interactions than full time workers and people who do not work have the lowest number of interactions. Regarding the residential location of the respondents (in Eindhoven vs. one of the surrounding villages), no significant differences were found.

Out of the 8074 social interactions (recorded by 747 respondents), 7339 social interactions (recorded by 742 respondents) were used in the analyses. This reduction is mainly due to the fact that we did not ask the respondents to record detailed information on all contacted persons if the interaction took place with more than 3 persons.

For our analyses we will examine whether a social interaction took place with a local tie. Although we collected detailed data on the people with whom the respondents interacted, we do not have the exact addresses of the contacted persons. We did ask respondents to report the distance between homes as a categorical variable, the first category being "within $1 \mathrm{~km}$ ". This first distance category was chosen because this reflects a walkable distance.

We also asked for the type of relationship with the persons they interacted with, such as relatives, friends, coworkers, fellow club members and neighbors/fellow residents. However, the relationship categories can sometimes overlap, for instance, coworkers can also be friends, and neighbors can also be relatives. Moreover, there may be considerable 
differences in what individuals consider neighbors or fellow residents, as people's activity spaces differ, which may lead to different perceptions of neighborhood. We therefore decided to define local ties as people living within $1 \mathrm{~km}$ of the respondent.

Out of the 7339 social interactions in our analyses, $1016(14 \%)$ took place with at least one local tie (someone living within $1 \mathrm{~km}$ ). A relatively large share of respondents $(48 \%)$ did not record any social interaction with a local alter in the two diary days, whereas only a very small share $(1 \%)$ of respondents recorded only contacts with local alters.

Table 3 shows a comparison of social interactions with at least one local tie versus social interactions with alters living further away. As shown, social interactions with local ties are more often face-to-face, whereas social interactions with alters living further away are more often via another communication mode (mainly telephone or internet). Regarding day of the week the results in Table 3 show that local ties are contacted more often during the weekend than non-locals. This is probably related to the fact that people spend more time at home (and thus in their residential area) during the weekend, compared to working days. Regarding the type of location we find that contacts with local alters more often take place at a home location or on the road/in public outdoor space. Table 3 shows that $57 \%$ of social interactions with local ties are spontaneous or coincidental contacts, versus $53 \%$ of social interactions with non-locals. The percentage of spontaneous social interactions seems high. However, it is in line with findings from Mohammadian and Doherty (2005) and Van Bladel et al. (2009) that social activities are among the most impulsively performed activities. The finding that the percentage of spontaneous social interactions with a local alter are higher was expected, as people living in close proximity have a higher chance of running into each other and having a spontaneous chat compared to people living further apart. Finally, the duration of social interaction with locals does not significantly

Table 3 Comparison of social interactions $(\mathrm{N}=7339)$ with local versus non-local ties

\begin{tabular}{|c|c|c|c|c|}
\hline & Local (\%) & Non-local (\%) & Total $(\%)$ & $\mathrm{X}^{2}(\mathrm{p}$ value $)$ \\
\hline \multicolumn{5}{|l|}{ Communication mode } \\
\hline Face-to-face & 71 & 45 & 48 & \multirow[t]{2}{*}{$228.329(0.000)$} \\
\hline Other mode & 30 & 55 & 52 & \\
\hline \multicolumn{5}{|l|}{ Day of the week } \\
\hline Weekend & 24 & 19 & 20 & \multirow[t]{2}{*}{$12.928(0.000)$} \\
\hline Weekday & 76 & 81 & 80 & \\
\hline \multicolumn{5}{|l|}{ Type of location } \\
\hline Home location & 66 & 61 & 62 & \multirow[t]{6}{*}{$139.261(0.000)$} \\
\hline Work location & 3 & 14 & 13 & \\
\hline School & 6 & 4 & 4 & \\
\hline Sports location & 4 & 3 & 3 & \\
\hline On the road/public space outdoors & 13 & 7 & 8 & \\
\hline Other location & 9 & 10 & 10 & \\
\hline \multicolumn{5}{|l|}{ Pre-arranged versus spontaneous } \\
\hline Planned & 29 & 30 & 30 & \multirow[t]{3}{*}{$10.172(0.006)$} \\
\hline Routine & 17 & 14 & 17 & \\
\hline \multirow[t]{2}{*}{ Spontaneous/coincidental } & 57 & 53 & 53 & \\
\hline & & & & t (p value) \\
\hline Duration (min) & 42.40 & 40.86 & 41.07 & $0.574(0.566)$ \\
\hline
\end{tabular}




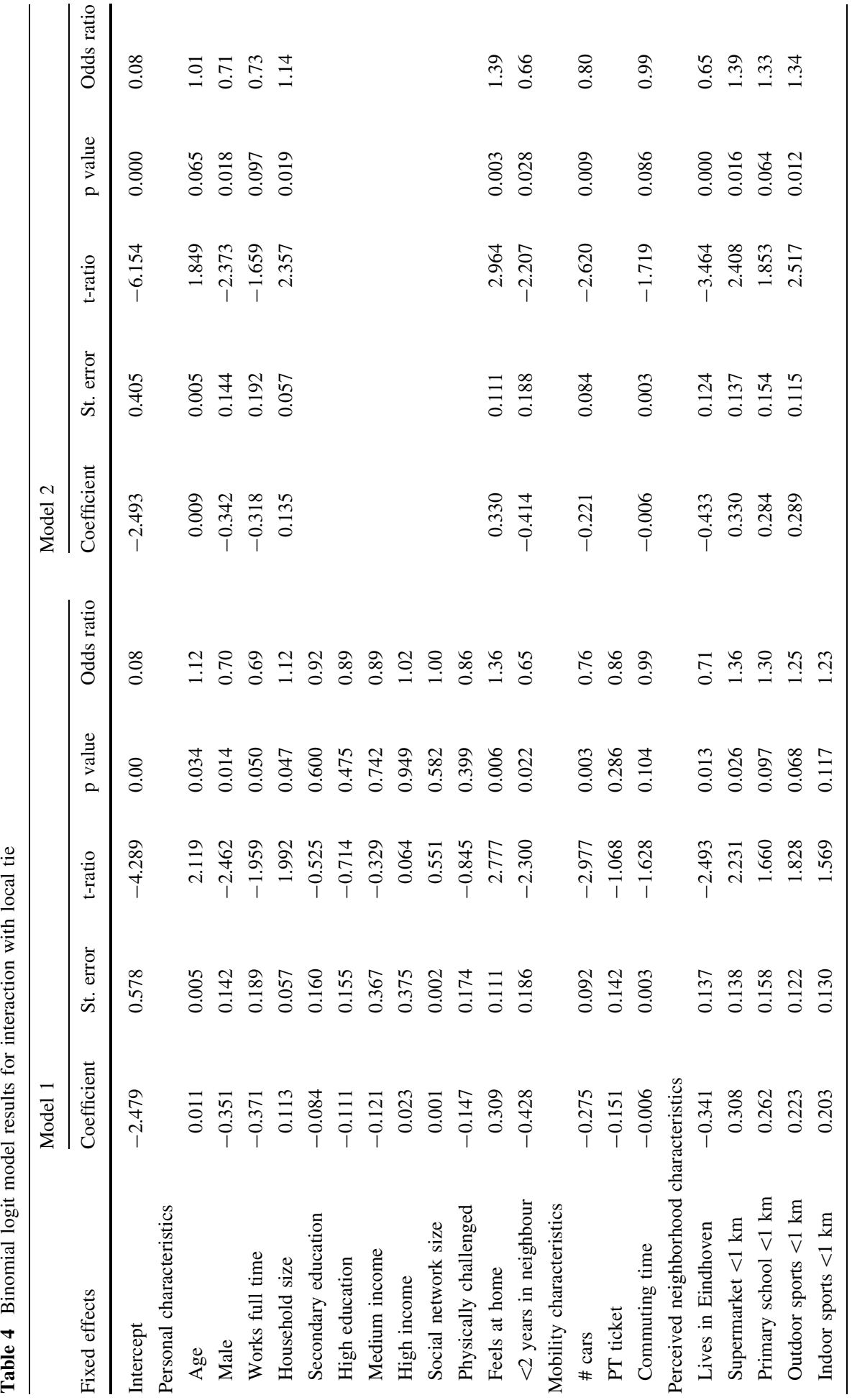




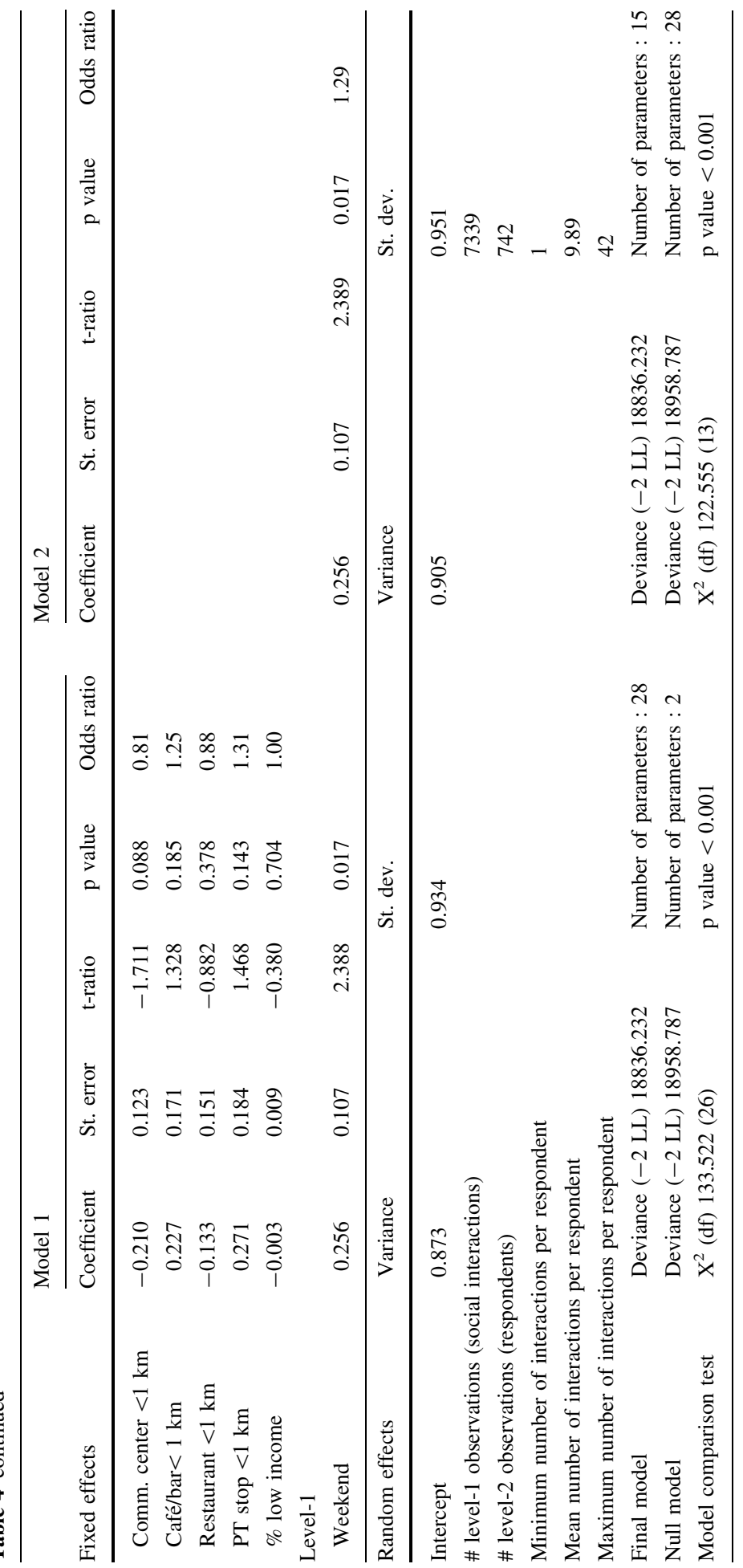


differ from the duration of social interaction with others. For both the average duration is a little over half an hour.

\section{Methods and results}

The dependent variable in our analyses is a binary variable (the social interaction took place with an alter living within $1 \mathrm{~km}$ or not). In addition, the data have a hierarchical structure (multiple interactions per respondent). Therefore, we probably cannot treat the social interactions from the same respondent as independent observations. Instead, they have to be treated in clusters. Therefore, a two level logistic regression model is estimated.

Consider a level-1 outcome $Y_{i j}$ taking on a value of 1 (the social interaction took place with a local alter) with conditional probability $p_{i j}$. Then the logit model or the generalized linear model for (level-1) interaction $i$ nested in (level-2) respondent $j$ is:

$$
\ln \left[\frac{p_{i j}}{1-p_{i j}}\right]=\eta_{i j}=\beta_{0}+\beta_{1} X_{i j}
$$

where $\beta$ is a vector of coefficients and $X_{i j}$ is a vector of observed variables.

We used HLM 7 software to estimate the model. We used the full maximum likelihood method of estimation. We first estimated the null model to test whether there is a level-2 agency effect on the level-1 intercept. The variance component is significant $(p<0.001)$ which indicates that there is between-groups variance in the dependent variable and thus a multilevel model is appropriate. At the level of the interactions (level-1), we only estimate an intercept and a coefficient for whether or not the interaction took place during the weekend. We do not use the other variables shown in Table 3 as explanatory level-1 variables in the model, because we do not expect the choice between interacting with local alters versus non-local alters to be influenced by the type of interaction (communication mode, location, planned/coincidental or duration).

We used three groups of explanatory variables (personal and household characteristics, mobility characteristics and neighborhood characteristics) at the respondent level (level-2). First, a model containing all variables reported in Table 1 was estimated (model 1). Second, the variables that were insignificant at the 0.1 level were removed in a step-wise procedure, resulting in the final model (model 2). The estimation results of both models are shown in Table 4.

The results show that four personal characteristics significantly affect local social interaction. The positive coefficient indicates that older people are more likely to interact with fellow residents. This finding is in line with Völker and Flap (2007) who found that older people are more likely to have neighbors in their social network.

Men are found to be less likely to interact with a local tie. All else equal, men are 0.7 times as likely as women to interact with someone living within $1 \mathrm{~km}$. The same is found for people who work full time. Household size is found to have a positive effect on social interaction with local ties. These findings are probably all related to the time spent at home and in the neighborhood: women, people who work less and people with children on average spend more time at home, increasing their opportunities for social contact with locals. No significant effects were found for education level, income, social network size or having a disability.

Regarding the mobility characteristics, we found that social interaction with a local tie is less likely for people with more cars in the household. An extra car in the household 
decreases the odds of interacting with a local tie by $20 \%$. Regarding commuting time we found a small negative effect as well, indicating that people who travel longer to and from work, are less likely to interact with people who live within their neighborhood. These findings are plausible, as these mobility tools increase people's opportunities for activities outside the residential area. This is in line with Kowald et al. (2013) suggesting that people with a car and people with a season ticket for public transport have their social network members living further away.

The final set of explanatory variables are the residential characteristics. The results show that respondents living in Eindhoven were less likely to interact with a local tie. This suggests that local social contacts are more likely in smaller communities. We find that people who feel completely at home in the neighborhood are $39 \%$ more likely to interact with local alters compared to respondents who do not feel completely at home (all else equal). This is a plausible finding, although the direction of causality is unclear. People may have more local contacts if they feel more at home in the neighborhood and conversely, they may feel more at home in the neighborhood if they have more local contacts. The results also indicate that people who have been living in the neighborhood longer are 1.5 times as likely to interact with local alters compared to people who have been living in the neighborhood for less than 2 years.

Regarding the availability of facilities within walking distance (within $1 \mathrm{~km}$ from home) the results show that three types of facilities in their neighborhood are related to a higher likelihood of people interacting with fellow residents. These facilities are supermarkets, primary schools and outdoor sports facilities. People with a supermarket within $1 \mathrm{~km}$ are $39 \%$ more likely to interact with a local alter compared to people who have a supermarket further away. The finding of the importance of a supermarket within walking distance is in line with Hickman (2013), suggesting that local shops are valued for social interaction. People who have a primary school in their neighborhood are $33 \%$ more likely to interact with fellow residents. This finding is in line with other studies (e.g. Völker and Flap 2007; Van Eijk 2010; Van Beckhoven and Van Kempen 2003).

Finally, the results suggest that the likelihood of interacting with a local alter is 1.34 times as high for people who have an outdoor sports facility within $1 \mathrm{~km}$ from their home. One might expect the positive effects of living close to these facilities and living in a smaller town to neutralize each other, as larger cities often have more facilities. We did however check for correlations between living in Eindhoven and having these facilities within $1 \mathrm{~km}$ and did not find large positive correlations. A small positive correlation was found between living in Eindhoven and the presence of a supermarket $(\rho=0.229$, $\mathrm{p}<0.01$ ), a small negative correlation between living in Eindhoven and the presence of an outdoor sports facility $(\rho=-0.138, \mathrm{p}<0.01)$, and no significant correlation between living in the city and the presence of a primary school within $1 \mathrm{~km}(\rho=0.053$, n.s.). This suggests that the effects of living in the city and the presence of facilities do not annul each other. The presence of an indoor sports facility, community center, bar or restaurant does not affect social interaction with local alters. The presence of a public transport stop within $1 \mathrm{~km}$ was not found to significantly affect the likelihood of interacting with local alters either.

The model fit statistics show that the final model fits the data significantly better than the intercept-only model. However, the difference in deviances is not very large. This suggests that the choice for interacting with someone living close by can only to a small extent be explained by the personal, mobility and residential characteristics in our study. 


\section{Conclusions and discussion}

Assuming that local social interaction is important for people's quality of life and livability in neighborhoods, the aim of this study was to analyze to what extent social contacts take place with local others and how local social interaction is affected by personal characteristics, mobility attributes and characteristics of the residential environment. Based on social interaction diary data collected from 747 respondents in the Eindhoven area, a number of descriptive analyses were presented. In addition, a multilevel binomial logit model was estimated explaining whether a social interaction took place with a fellow resident (living within $1 \mathrm{~km}$ ).

Descriptive analyses of the data showed that most social contacts take place outside of the neighborhood. Almost half of the respondents did not have social contact with a local other during the two diary days and only $1 \%$ of the respondents recorded only local social interactions. However, still a significant share $(14 \%)$ of people's social interactions took place with local others. The neighborhood therefore still seems to be important for social interaction, at least for some people.

The results of the multilevel binomial model indicated that the likelihood of interacting with a fellow resident is affected by personal characteristics, mobility characteristics, as well as characteristics of the residential location. Regarding the personal characteristics we found significant effects for age, gender, household size and work. This is a finding that is in line with earlier findings. In addition, we found that mobility characteristics (car ownership and commuting time) decrease the likelihood of interacting with a fellow resident. All these findings typically indicate that people are more likely to interact with fellow residents when they spend more time in their residential area.

With respect to characteristics of the residential environment we found that people living in smaller towns were more likely to interact with a local tie. In addition, three types of facilities in the residential area (within $1 \mathrm{~km}$ ), namely supermarkets, primary schools and outdoor sports facilities were found to be related to a higher likelihood of interacting with local ties. Our findings are relevant for urban planners and policy makers. Many of them wonder about the best strategy regarding (social) facilities. The number and quality of local services and facilities has decreased over the last decades, due to increasing mobility, increasing use of the Internet (e-commerce), and economic recession. Moreover, the Netherlands as well as other countries are currently dealing with areas with demographic decline, where local facilities are disappearing because of a decreasing number of people living in the area. Our results suggest that local facilities provide opportunities for local contact and therefore increase the likelihood of local contacts. We would therefore advise policy makers to strive to maintain these types of facilities, as they can have a positive effect on the livability and quality of life of residents, especially for less mobile groups (e.g. elderly people, or people without a car). Although we found evidence that local facilities may increase local contacts, our methods do not allow for causal inferences. Therefore, the opposite is also possible, for instance that the local facilities are maintained because of the local contacts there, and other facilities disappear because the local contact at these facilities is not valued. This suggests that further research into the importance of local facilities for local social interaction and people's quality of life is desired, especially for regions where facilities are disappearing because of demographic decline.

In addition, our results are relevant for transportation policy and planning, as social interactions are responsible for a large and growing segment of travel. Local social interactions constitute a specific travel demand, in the sense that they usually involve short 
distances which are suited for non-motorized transport modes, such as walking and cycling. Our results show that more mobile people are less likely to interact with local alters compared to alters at a larger distance. Different mobility tools provide opportunities to maintain social ties over large distances. Although we claim that local social interactions are important for people's quality of life and neighborhood livability, this does not mean that people with more local contacts are happier or more satisfied than people with more far-flung contacts. The relationship between social activity-travel and social satisfaction is a topic that deserves more attention in future research.

Although our study provides interesting insights in the factors influencing local social interaction, the results of our study are shaped by the way we defined the concepts 'local' and 'social interaction'. Regarding the definition of social interaction, greeting someone was not included. However, this is a type of contact that probably occurs relatively often among fellow residents and that may be relevant for the formation of local ties and for people's perception of connectedness to their neighborhood. In addition, our definition of local, as being within $1 \mathrm{~km}$, can be disputed. We chose this distance boundary as we consider it a walkable distance. However, individuals' perceptions of a walkable distance may differ, as well as their (social) activity spaces. Moreover, bicycle use is more important than walking in the Netherlands. It may thus well be that a considerable part of local trips are made by bike.

Our results showed that the likelihood of interacting with a local alter can only to a small extent be explained by the personal, mobility and residential characteristics that were included in our study. This raises the question of which variables could be included to better explain local social contact. Relating to the discussion in the previous paragraph, it may be worthwhile to include more variables regarding individuals' perception of their neighborhood, including their perception of safety in the neighborhood and neighborhood boundaries, their social activity spaces, as well as walkability of the neighborhood.

Finally, we only analyzed whether or not a social interaction took place with a fellow resident. We did not collect information on the content of the social interaction, or the value it had for the respondents' quality of life. Further research into the importance of local social interactions would be desirable, in order to find out to what extent local communities still matter and how important local contacts are for people's quality of life and social cohesion in neighborhoods.

This study has shown that social interactions and their distance patterns are related to personal characteristics, mobility and the built environment. Social interactions are important for people's wellbeing. A lack of social contact results in a higher risk of social isolation and loneliness, which in turn carries the risk of being less physically active, and having reduced mental and physical health. It is therefore important to provide opportunities for social interaction. Mobility tools can provide these opportunities. However, for people who are less mobile and therefore more dependent on their neighborhood, it is important that the neighborhood provides these opportunities as well. This study provides some insights on how to create living environments where local social interaction is encouraged, however, further research in this area remains imperative.

Open Access This article is distributed under the terms of the Creative Commons Attribution 4.0 International License (http://creativecommons.org/licenses/by/4.0/), which permits unrestricted use, distribution, and reproduction in any medium, provided you give appropriate credit to the original author(s) and the source, provide a link to the Creative Commons license, and indicate if changes were made. 


\section{References}

Arentze, T.A., Timmermans, H.J.P.: Social networks, social interactions, and activity-travel behavior: a framework for microsimulation. Environ. Plan. B 35, 1012-1027 (2008)

Atkinson, R., Kintrea, K.: Disentangling area effects: evidence from deprived and non-deprived neighbourhoods. Urban Stud. 38, 2277-2298 (2001)

Axhausen, K.W.: Social networks and travel: some hypotheses. In: Donaghy, K.P., Poppelreuter, S., Rudinger, G. (eds.) Social dimensions of sustainable transport: transatlantic perspectives, pp. 90-108. Ashgate, Aldershot (2005)

Baym, N., Zhang, Y.B., Lin, M.-C.: Social interaction across media: interpersonal communication on the internet, face-to-face, and telephone. New Media Soc. 6, 41-60 (2004)

Boase J, Horrigan J, Wellman B, Rainie L (2006) The Strength of Internet Ties. Washington, DC: Pew Internet and American Life Project. http://www.pewinternet.org/ /media/Files/Reports/2006/PIP_ Internet_ties.pdf.pdf Accessed 11 June 2013

Bridge G (2002) The neighborhood and social networks. Centre for Neighborhood Research, paper 4, http:// www.neighbourhoodcentre.org.uk

Carrasco, J.A., Cid-Aguayo, B.: Network capital, social networks, and travel: an empirical illustration from Concepción, Chile. Environ. Plan A 44, 1066-1084 (2012)

Carrasco, J.A., Miller, E.J.: Exploring the propensity to perform social activities: a social networks approach. Transportation 33, 463-480 (2006)

Delmelle, E.C., Haslauer, E., Prinz, T.: Social satisfaction, commuting and neighborhoods. J. Transp. Geogr. 30, 110-116 (2013)

Dempsey, N., Brown, C., Bramley, G.: The key to sustainable urban development in UK cities? The influence of density on social sustainability. Prog. Plan. 77, 89-141 (2012)

Dugundji ER, Páez A, Arentze TA, Walker JL with contributions from Carrasco JA, Marchal F, Nakanishi H (2011) Transportation and social interactions. Transp. Res Part A 45: 239-247

Du Toit, L., Cerin, E., Leslie, E., Owen, N.: Does walking in the neighbourhood enhance local sociability? Urban Stud. 44, 1677-1695 (2007)

Farber, S., Neutens, T., Miller, H.J., Li, X.: The social interaction potential of metropolitan regions: a timegeographic measurement approach using joint accessibility. Ann. Assoc. Am. Geogr. 103, 483-504 (2013)

Fischer, C.S.: To dwell among friends: personal networks in town and city. University of Chicago Press, Chicago (1982)

Forrest, R., Kearns, A.: Social cohesion, social capital and the neighborhood. Urban Stud. 38, 2125-2143 (2001)

Francis, J., Giles-Corti, B., Wood, L., Knuiman, M.: Creating sense of community: the role of public space. J. Environ. Psychol. 32, 401-409 (2012)

Fu, Y.-C.: Contact diaries: building archives of actual and comprehensive personal networks. Field Methods 19, 194-217 (2007)

Galster, G.: Should policy makers strive for neighborhood social mix? An analysis of the Western European evidence base. Hous. Stud. 22, 523-545 (2007)

Granovetter, M.S.: The strength of weak ties. Am. J. Sociol. 78, 1360-1380 (1973)

Guest, A.M., Wierzbicki, S.K.: Social ties at the neighborhood level: two decades of GSS evidence. Urban. Aff. Rev. 35, 92-111 (1999)

Hanibuchi, T., Katsunori, K., Nakaya, T., Shirai, K., Hirai, H., Kawachi, I.: Does walkable mean sociable? Neighborhood determinants of social capital among older adults in Japan. Health Place 18, 229-239 (2012)

Hickman, P.: "Third Places" and social interaction in deprived neighbourhoods in great Britain. J Hous. Built Environ. 28, 221-236 (2013)

Hipp, J., Perrin, A.J.: The simultaneous effect of social distance and physical distance on the formation of neighborhood ties. City Commun. 8, 5-25 (2009)

Kleinhans, R.: Social implications of housing diversification in urban renewal: a review of recent literature. J Hous. Built Environ. 19, 367-389 (2004)

Kowald, M., Axhausen, K.W.: Focussing on connected personal networks: selected results from a snowball sample. Environ. Plan. A 44(5), 1085-1100 (2012)

Kowald, M., van den Berg, P.E.W., Frei, A., Carrasco, J.A., Arentze, T.A., Axhausen, K.W., Mok, D., Timmermans, H.J.P., Wellman, B.: Distance patterns of personal networks in four countries: a comparative study. J. Transp. Geogr. 31, 236-248 (2013)

Larsen, J., Urry, J., Axhausen, K.W.: Mobilities, networks. Geographies, Ashgate (2006) 
McPherson, M., Smith-Lovin, L., Brashears, M.E.: Social isolation in America: Changes in core discussion networks over two decades. Am. Sociol. Rev. 71(3), 353-375 (2006)

Mohammadian, A., Doherty, S.: A mixed logit model of activity scheduling time horizon incorporating spatial-temporal flexibility variables. Transp. Res. Rec. 1926, 33-40 (2005)

Mokhtarian, P.L., Salomon, I., Handy, S.L.: The impacts of ict on leisure activities and travel: a conceptual exploration. Transp 33, 263-289 (2006)

Neutens, T., Farber, S., Delafontaine, M., Boussauw, K.: Spatial variation in the potential for social interaction: a case study in Flanders (Belgium). Comput. Environ. Urban Syst. 41, 318-331 (2013)

Oldenburg, R.: The great good place. Marlow, New York (1989)

Pinkster, F., Völker, B.: Local social networks and social resources in two Dutch neighbourhoods. Hous. Stud. 24, 225-242 (2009)

Putnam, R.: Bowling alone: The collapse and revival of American Community. Simon \& Schuster, New York (2000)

Ronald, N.A., Dignum, V., Jonker, C., Arentze, T.A., Timmermans, H.J.P.: On the engineering of agentbased simulations of social activities with social networks. Inf. Softw. Technol. 54, 625-638 (2012)

Ronald, N.A., Arentze, T.A., Timmermans, H.J.P.: The effects of different interaction protocols in agentbased simulation of social activities. Int J Agent Technol. Syst. 3(2), 18-32 (2011)

Sampson, R.J.: Collective efficacy theory: lessons learned and directions for future inquiry. In: Cullen, F.T., Wright, J.P., Blevins, K. (eds.) Taking stock: The status of criminological theory. Advances in Criminological theory, vol. 15. Transaction Publishers, New Brunswick (2006)

Schlich, R., Schönfelder, S., Hanson, S., Axhausen, K.W.: Structures of leisure travel: temporal and spatial variability. Transp. Rev. 24(2), 219-237 (2004)

Talen, E.: The social doctrine of new urbanism. Urban Stud. 36, 1361-1379 (1999)

Thomése, F., Van Tilburg, T.: Neighbouring networks and environmental dependency. Differential effects of neighborhood characteristics on the relative size and composition of neighbouring networks of older adults in The Netherlands. Ageing Soc. 20, 55-78 (2000)

Tillema, T., Dijst, M., Schwanen, T.: Face-to-face and electronic communications in maintaining social networks: the influence of geographical and relational distance and of information content. New Media Soc 12, 965-983 (2010)

Van Beckhoven, E., Van Kempen, R.: Social effects of urban restructuring: a case study in Amsterdam and Utrecht, the Netherlands. Hous. Stud. 18, 853-875 (2003)

Van Bladel K, Bellemans T, Janssens D, Wets G (2009) Activity-travel planning and rescheduling behavior: an empirical analysis of influencing factors. Proceedings of the 88th Annual Meeting of the Transportation Research Board, Washington D.C

Van den Berg, P.E.W., Arentze, T.A., Timmermans, H.J.P.: Size and composition of ego-centered social networks and their effect on travel distance and contact frequency. Transp. Res. Rec. 2135, 1-9 (2009)

Van den Berg, P.E.W., Arentze, T.A., Timmermans, H.J.P.: Estimating social travel demand of senior citizens in the Netherlands. J. Transp. Geogr. 19, 323-331 (2011)

Van den Berg PEW, Timmermans HJP (2013) A multilevel path analysis of social networks and social interaction in the neighborhood, Paper presented at the 20th Annual Conference of the European Real Estate Society, Vienna, 3-6 July

Van den Berg, P.E.W., Arentze, T.A., Timmermans, H.J.P.: New ICT's and social interaction: modelling communication frequency and communication mode choice. New Media Soc. 14, 987-1003 (2012)

Van der Poel, M.G.M.: Delineating Personal Support Networks. Soc. Netw. 15, 49-70 (1993)

Van Eijk, G.: Does living in a poor neighborhood result in network poverty? A study on local networks, locality-based relationships and neighborhood settings. J Hous. Built Environ. 25, 467-480 (2010)

Van Kempen, R., Bolt, G.: Social cohesion, social mix, and urban policies in the Netherlands. J Hous. Built Environ. 24, 457-475 (2009)

Völker, B., Flap, H.: Sixteen million neighbors. A multilevel study of the role of neighbors in the personal networks of the Dutch. Urban Aff Rev 43, 256-284 (2007)

Wellman, B.: The community question: the intimate network of East Yorkers. Am. J. Sociol. 84, 1201-1231 (1979)

Wellman, B.: Physical space and cyberspace: the rise of personalized networking. Int. J Urban Reg. Res. 25, 227-252 (2001)

Pauline van den Berg is an assistant professor of Real Estate Management and Urban Development at the Eindhoven University of Technology. She holds a MSc in Cultural Anthropology (Catholic University of Nijmegen), a MSc in Architecture, Building and Planning (Eindhoven University of Technology) and a Ph.D. in Urban Planning (Eindhoven University of Technology). Her research focuses on the impact of 
residential environments on human behavior and quality of life, the spatial distribution of leisure and social activities and their consequences for urban and transport planning.

Theo Arentze is full professor of Real Estate and Urban Systems and chair of the Real Estate Management and Development group at the Eindhoven University of Technology. His research interests include choice behavior of users of the built environment, multi-actor decision making and large-scale simulation of urban and transport systems.

Harry Timmermans is chaired Professor of the Urban Planning Group at the Eindhoven University of Technology. He studied at the Catholic University of Nijmegen and holds a Ph.D. degree in Geography/ Urban and Regional Planning. His main research interests concern the study of human choice processes, mathematical modelling of urban systems and spatial interaction and choice patterns and the development of decision support and expert systems for application in urban and transport planning. 